\title{
Building with Nature as integrated design of infrastructures
}

\section{Nikki Brand ${ }^{1,2}$, \& Marcel Hertogh ${ }^{2}$}

1. Delft University of Technology, University Corporate Office, Department of Strategic Development

2. Delft University of Technology, Faculty of Civil Engineering and Geosciences, Department of Materials, Mechanics, Management \& Design (3MD) 


\section{Abstract}

Many people associate Building with Nature with its flagship project, the Sand Motor. This mega-nourishment redefined the role of natural processes in civil engineering projects, demonstrating that instead of 'do no harm' as the highest possible supporting goal of coastal infrastructure, the design could incorporate natural processes to attain societal and ecological goals. As such, the Sand Motor represents a key example of the integrated design of civil infrastructures. In this contribution, we pursue an improved understanding of the integrated design of civil infrastructures, by comparing the illustrative example of the Sand Motor against a framework based on transport infrastructures and the occasional flood defence. It turns out that application of a framework from one domain to another - a conscious act of interdisciplinary learning - results in a modification of that framework. Although the domain of Building with Nature fits well with many existing attributes of integrated design for civil infrastructures (the life cycle approach, adaptive design and adding functionalities), its key attribute (dynamics) adds a unique box to the integrality index. This intellectual effort raises two issues. It demonstrates that our understanding of integrated design is rather specific for different infrastructure-domains. Second, it is likely that the bandwidth of uncertainty that is key to the incorporation of natural processes in infrastructure design, and the changing behaviour of the structure itself in the maintenance phase, has implications for the governance regime of such infrastructures.

\section{KEYWORDS}

Building with Nature, Sand Motor, life cycle approach, adaptive design, infrastructures 


\section{Introduction}

Despite ubiquitous calls for interdisciplinary research, the conscious, strategic pursuit of such learning is often an exception to the rule (INTREPID, 2019). Multidisciplinary research packages remain the trend, and measures to integrate learning throughout the research process are established 'on the go' (DIMI, forthcoming). While on the one hand, multidisciplinary research is often sold as far more ambitious than interdisciplinary research, we suspect it is quite common that many scholars pursue interdisciplinary learning unknowingly. Scholars can also make interdisciplinary cognitive connections on an intrapersonal level (Pfirman \& Martin, 2017). Interpersonal, collegial connections in team-collaboration within a university department are also systemic, especially among disciplines that are closely related to one another such as urban planning and urban design. Such curiosity-driven interactions occur daily and are likely the engine behind the creation of new academic disciplines (Lyall, 2008; Gibbons et al., 2010), although, as a rule of thumb, integrative learning is not done explicitly (Tress et al., 2005). It is possible that interdepartmental, cross-field connections on topics that sit at the intersection of multiple disciplines may be the most challenging type and this is where awareness about the methodology of interdisciplinary learning could facilitate integrative learning. This is especially the case when such problem-oriented research engages multiple stakeholders outside of academia, and a full inter- and transdisciplinary research project develops (Pfirman \& Martin, 2017; Rhoten \& Pfirman 2007; Tress et al., 2005). This chapter therefore aims to explicitly pursue interdisciplinary thinking, with a twofold aim.

1. First, we ask how the application of an integrated design methodology from the domain of civil infrastructure to the concept of building with nature changes the understanding of integrated design.

2. Second, by consciously selecting the why and how of an interdisciplinary learning strategy, we reflect on the presumed benefits of such integrative reasoning.

The chapter is structured as follows. In the first section, we outline key notions of interdisciplinary research and its presumed contribution to learning. Second, we explain integrated design methodology as derived from the topic of transportation infrastructures and the occasional flood defence. In the third section, building with nature's flagship example of the Sand Motor will be contrasted with features of different forms of integrated design in the civil infrastructure domain. How does the Sand Motor fit into our current understanding of integrated design of civil infrastructures and should that understanding be adapted? After a discussion of results, we conclude with the implications of this study, including a reflection on interdisciplinary learning. 


\section{Interdisciplinarity as a means for research}

Interdisciplinary research - which we define as the act of interdependent learning strategies of different academic disciplines - is considered as the key vehicle to pursue knowledge and contributes to the solution of complex (socio-scientific) problems, where one discipline on its own cannot provide an answer (Lyall, 2008). Despite the increase in availability of scientific knowledge, decisive action regarding persistent, complex problems including climate change, biodiversity loss and related issues such as poverty, security and governance has been very slow (Hirsh Hadorn et al., 2008). While transdisciplinary research - learning that involves stakeholders - is considered as a means to overcome the mismatch between knowledge production in academia and knowledge requests for solving societal problems (Hoffman-Riem et al., 2008), interdisciplinary learning targets the knowledge fragmentation that undermines the capacity of society to address its complex problems. The promise of interdisciplinary research is therefore in delivering what has been called 'systems knowledge' (ProClim, 1997; COST, 2014). However, despite the urgent call for interdisciplinary learning, the organisational barriers for such work within the university's structures are large (Pfirman \& Martin, 2017), the rate of progress has been slow (National Academy of Sciences et al., 2005; Krull, 2000) and confusion about the state of the art abounds (Tress et al., 2005), resulting in the term being used as window-dressing for what, in fact, is multidisciplinary research (COST, 2019). Lyall (2008) identified at least seven motivations to pursue interdisciplinary learning, as summed up below:



To summarize, interdisciplinarity can therefore be a means of research in four main cases: for (1) particular objects or domains, (2) knowledge transfer to real-life applications, (3) is user- or stakeholder-driven (transdisciplinary) work or (4) for overcoming academic obstacles. 
The objective of this paper fits with the first and the last of these cases. First, the Sand Motor can be considered as an interdisciplinary research object, that can be addressed by a multitude of disciplines like coastal engineering, ecology, landscape architecture and civil infrastructure design. Second, our goal to consider Building with Nature from the perspective of civil infrastructure design purely for the sake of intellectual reasoning - a better understanding of integrated design of civil infrastructures - is purely academically-oriented. Having clarified why the objective of this chapter is interdisciplinary, we can consciously select a learning strategy, again following Lyall (2008).

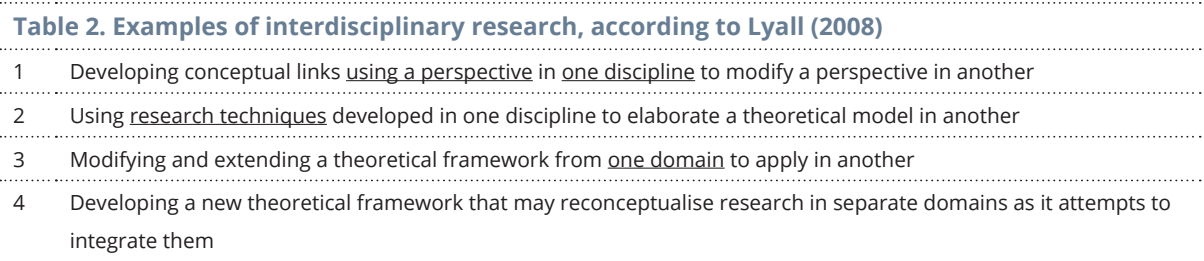

From the four options outlined above, this chapter modifies and extends the theoretical framework from one domain - integrated design of civil infrastructures - to the emerging domain of Building with Nature, with the Sand Motor as an 'interdisciplinary object' or case-study. We can therefore expect the theoretical framework of integrated design to be revalued and perhaps altered, based on its application to the interdisciplinary building with nature-domain; in other words, stimulating 'new modes of thinking'.

\section{Integrated design of civil infrastructures}

In the larger domain of integrated design, many different understandings of the concept exist (Hertogh et al., 2018; Visser, 2020). In this contribution, we depart from examples of integrated design that were studied in our section - Integrated Design and Management - and were published in a previous publication (Hertogh et al., 2018). It is key to note that all of these case-studies are civil infrastructures, and that our perspective is likely influenced by the origins of civil engineering. Below, these 6 different forms of integrated design are listed. Key to understanding the different notions of integration is the rejection of the notion that infrastructure design in particular can be reduced to a single, sectoral objective with a mono-functional solution for a simplified design problem. To give a better impression of the different notions and their implications, we have included an example project for each form of integrated design and their key attributes. 


\begin{tabular}{|c|c|c|c|}
\hline \\
\hline \multicolumn{4}{|c|}{$\begin{array}{l}\text { Different forms of integrated design } \\
\text { Type } \\
\text { Key attribute(s) }\end{array}$} \\
\hline 1 & Fit to different scales of design & Adding design requirements & North-South subway, Amsterdam \\
\hline 2 & $\begin{array}{l}\text { Decomposition of the design } \\
\text { (systems-engineering) }\end{array}$ & $\begin{array}{l}\text { Effective breakdown of work } \\
\text { packages in a mega-engineering } \\
\text { project, with individual (design) } \\
\text { requirements disciplinary, } \\
\text { sometimes geographically }\end{array}$ & $\begin{array}{l}\text { High Speed Line, railway } \\
\text { Amsterdam-Antwerp } \\
\text { (Hertogh et al., 2008) }\end{array}$ \\
\hline 3 & Three-layer model & $\begin{array}{l}\text { Interaction between layers and their } \\
\text { timescale adds design requirements: }\end{array}$ & $\begin{array}{l}\text { Long-term decision-making in } \\
\text { spatial planning; Sophia Rail Tunnel } \\
\text { with enlarged diameter } \\
\text { (Stive, 1999) }\end{array}$ \\
\hline 4 & Life cycle model & $\begin{array}{l}\text { Incentivises contractor to pursue } \\
\text { designs that are costlier to build, but } \\
\text { cheaper to maintain }\end{array}$ & $\begin{array}{l}\text { Design-build-finance-maintenance } \\
\text { (DBfM contracts) }\end{array}$ \\
\hline 5 & Adaptive design & $\begin{array}{l}\text { No-regret as a key design } \\
\text { requirement }\end{array}$ & Section ring road Antwerp \\
\hline 6 & $\begin{array}{l}\text { Multifunctional design } \\
\text { (Visser, 2020) }\end{array}$ & $\begin{array}{l}\text { Adding design requirements for } \\
\text { different functions }\end{array}$ & Katwijk flood defense \\
\hline
\end{tabular}

Table 3. Six different forms of integrated design according to Hertogh et al., 2018. All forms of integrated design add design requirements to the design objective, while others seek efficiency in an effective break down of work packages.

Our working hypothesis is that different understandings of integrated design from the narrow domain of civil infrastructures can be explained, first, from paradigm shifts in design management: most notably the shift from a deterministic perspective to a complexity perspective (Hertogh \& Westerveld, 2010). This paradigm shift puts more emphasis on interrelatedness of design variables, openness, and an acknowledgement that reality is knowable and controllable by a reductionist approach to problem-solving. A second factor that likely determines the differences between notions of integrated design is the design problem that they aim to tackle. Do note that with the exception of the three-layer model, all forms target large-scale (public) transportation or flood defences as examples of civil infrastructures. The three-layer model is applied in spatial decision-making processes, where the competition for space between different land uses is mitigated (ESPON, 2015). Rather than delivering a design itself, the layer-model is used to guide policy that informs the design of future infrastructures and land-use development. Third, it is key to note here that the three-layer model originates from the discipline of landscape architecture (De Hoog et al.,1998), and multifunctional design (of flood defences) is a hybrid between hydraulic engineering and spatial design (Voorendt, 2017). Interdisciplinary synthesis of knowledge in this domain has thus previously resulted in a different understanding of the integrated design of civil infrastructures. 


\section{The Sand Motor and the integrality index}

A key follow-up question is therefore what the theoretical framework for integrated design of civil infrastructures currently looks like. In the previous section, we noted that there is no consensus about what integrated design of civil infrastructures actually is - rather about what it is not - and that the current understanding is that it appears in different forms, representing different attributes of integration within the design. To move forward, we chose a practical solution: we listed the key attributes that distinguish the different forms of such integrated design and presented them as an index, on which the example-case for Building with Nature - the Sand Motor - can be 'scored' This flagship project of Building with Nature is a pilot project in the form of a large sandy peninsula: 21.5 million $\mathrm{m}^{3}$ sand deposited in front of the coastline near The Hague in 2011 (van Oudenhoven et al., 2019). The pilot monitors the state and the functioning of the coastal ecosystem, after sand nourishment has been implemented as a solution to prevent coastline erosion. While sand nourishment as public flood safety infrastructure has been standard practice in the Netherlands since the early 1990s, the Sand Motor is "...unique due to its size, the design philosophy behind it, and its multifunctionality" (Van Oudenhoven et al., 2019). Five times the size of an average nourishment, the Sand Motor is expected to disperse along the adjacent coastline using the natural forces of tides, waves and wind. The design philosophy is one of Building with $\mathrm{Na}-$ ture, an "integrated approach that harmonizes coastal management solutions with the requirements of ecosystems" (Ibidem). Multifunctionality is sought in the combination of the primary function of coastal protection (or flood safety) with leisure opportunities in the form of a new natural landscape. The Sand Motor can therefore be seen as a new example of integrated design of civil (flood safety) infrastructure. We can analyse the integrality of the Sand Motor's design according to the attributes derived from the existing framework listed below:

\begin{tabular}{|c|c|c|}
\hline \multicolumn{2}{|r|}{$\begin{array}{l}\text { Table 4. Six key attributes of integrate } \\
\text { integrality index for infrastructures }\end{array}$} & Sand Motor \\
\hline 1 & Requires different scales for design & $\begin{array}{l}\text { No, not in terms of higher and lower-scale } \\
\text { working packages }\end{array}$ \\
\hline 2 & Requires a geographical or disciplinary break down for design & $x$ \\
\hline 3 & $\begin{array}{l}\text { Requires scale and speed of change to be involved in consideration } \\
\text { of higher-tier layers or functionalities }\end{array}$ & $\begin{array}{l}\text { No, not in the sense of over-dimensioning } \\
\text { to compensate for inertia in affected tier } \\
\text { and to accommodate change in higher tiers }\end{array}$ \\
\hline 4 & Considers the maintenance phase explicitly & $x$ \\
\hline 5 & No-regret as key & $x$ \\
\hline 6 & Functional dominance? & $x$ \\
\hline
\end{tabular}


The first attribute, different scales of design, can be discarded after some deliberation. The Sand Motor obviously consists of an enormous number of grains of sand, but different components of the nourishment cannot be designed (or controlled) at different scales. Obviously, the Sand Motor can be broken down in several components (see for example Hoonhout, 2019, who noted sand, fine silt and clay fractions, and coarse elements) in its constitution. It can also be broken down geographically, like the intertidal beach, the lower dry beach and the upper dry beach. When the project is compared however to the North-South Line example project - where everything is designed from handrail to tunnel - it turns out that the key difference is that the Sand Motor is not required to meet the design requirements immediately. As Wijnberg $(2019,105)$ stated: "Contrary to hard engineering measures, the Sand Motor is not a static intervention that needs to meet all its goals upon completion when the contractors have finished their work. The Sand Motor is a dynamic intervention where nature is actually the master builder that should ensure that all goals are met over time." The project does contain the second attribute - disciplinary break down for design: modelling the behaviour of below-water development, and the above-water development based upon Aeolian transport. According to Wijnberg (2019), the second was based on past dune growth rates as numerical models predicting above-water development with computer simulations were lacking. Third, although the Sand Motor obviously has a long-term planning horizon (as all engineering measures are designed with a certain life-time in mind) it is not an integrated design in the sense of the three-layer model. The Sophia Rail-tunnel, for example, was deliberately oversized because of its location in two layers with the lowest pace of transformation in the three-layer model: the substratum and networks (Stive, 1999). Acknowledging the higher speed of change in the highest-tier layer (occupation) and the relative inertia of the second layer (networks), the tunnel was designed with a larger diameter. This will accommodate stacked transport if the demand arises in the future. The Sand Motor, when compared with the Sophia-tunnel example, is part of the substratum-layer but was not over-dimensioned to accommodate future changes in the first occupation-layer. Moreover, the design-life of the Sand Motor is a mere twenty years, which is shorter than the speed associated with the third, subsurface layer. Fourth, the Sand Motor does match the type of integrality that we associate with the life-cycle model and the example of Design-Build-Finance-Maintain (DBfM) contracts used in the construction industry. The key issue of DBM is that they incentivize contractors to pursue designs that are costlier to build, but cheaper to maintain. This is also key for the Sand Motor, which acknowledges the maintenance-phase explicitly. The project is oversized compared to the traditional coastal nourishment projects (that occur more often), dispersing the sediment along a larger stretch of coastline using the natural forces of tide, waves and wind. Nourishment 
therefore has to occur less often. It should be noted however that the Sand Motor's design is not so much driven by the optimisation of maintenance costs, but by harmonisation with the ecosystem and the delivery of ecosystem services (Van Zanten, 2016). Fewer nourishments cause fewer disturbances in the ecosystem. Fifth, this flagship Building with Nature project is a no-regret design. Due to its soft-engineering nature, it does not prematurely close off future pathways to other coastal solutions in case of sea level rise or other key factors in flood safety. Sixth and last, the Sand Motor definitely does check the integrality-box for multifunctional design, incorporating flood safety, ecosystem balance and recreation in one design. In its multifunctionality, the Sand Motor is comparable to Katwijk's flood defence, in that it combines flood safety with underground parking and a more attractive, natural-looking coastline. It needs to be noted here that Katwijk also attracts direct financial benefits (parking fees) whereas the economic benefits of the Sand Motor's recreational function are indirect.

\section{Results}

From the perspective of integrated design, the Sand Motor, as an example of Building with Nature, ticks many boxes of the integrality-index. Four out of six attributes associated with different forms of our current understanding of integrated design fit with Building with Nature's flagship project. The rather dynamic nature of the engineering project, and the fact that the mega-nourishment cannot be broken down in smaller components that can be designed and controlled upon completion of the project, is the attribute that sets this Building with Nature project apart from the current collection of integrated projects. Strikingly, the reason why two boxes in the index are not checked can be found in the new form of integrality that is presented by Building with Nature: its dynamic nature that changes within a bandwidth provided by natural forces that cannot be forecasted precisely. This does not allow for a breakdown according to scale. The three-layer model's application to Building with Nature is somewhat problematic here. In this case, the engineering intervention affects the lowest and, theoretically slowest, layer, the underground, while its lifecycle is so short as not to facilitate permanent settlement patterns. Possibly, this would not be the case for Building with Nature-projects that target another layer, for example tsunami forests that target the highest layer. What unites examples of Building with Nature (sediment nourishment, oyster reefs and tsunami-forests) is that they often partner with dynamic, natural forces. This raises the question if the notion of scalar breakdown is not incompatible with Building with Nature-type integrality. 
Overall, we can conclude that Building with Nature, when viewed as a particular form of integrated design of infrastructures with the Sand Motor as an example project, it fits particularly well with the lifecycle approach, adaptive design and adding functionalities. However, we argue that Building with Nature deserves to add its own box to the integrality-index (rather than being seen as a subcategory of multifunctional design) due to its unique attribute, dynamics. Obviously, the dynamics of natural forces represents a different form of functionality than precisely engineered co-functions. When reflecting on the presumed benefit of the interdisciplinary learning strategy followed above, this outcome is not surprising. The purpose of applying an existing framework to a new domain is to evaluate it, and in this case, is adds to the scope of a framework that was initially created for infrastructure in the form of hard engineering measures.

\section{Implications}

This explicit interdisciplinary research effort has two implications: one about our expectations of interdisciplinary work, and the second about the management of Building with Nature projects. In 2019, Building with Nature approaches hold great appeal for research design projects with cross-disciplinary objectives, as is demonstrated by concepts that include oyster reefs and mangrove forests for flood protection. However, we need to be explicit about how and why we are performing interdisciplinary research, and how the results are different because of it. As a rule, interdisciplinary learning is often used as a window-dressing term for what is, in fact, multidisciplinary learning, undermining the credibility of actual interdisciplinary work. This risks the dismissal of interdisciplinary learning for the wrong reasons. In the above example, where curiosity-driven interdisciplinary learning has been used for intellectual reasons, it has changed the existing understanding of integrated design. Moreover, it also raises the issue of how determinative certain research domains are for the theoretical frameworks we use. In this case, our understanding of integrated design came from the domain of civil infrastructures: geared towards transport, and with an occasional multifunctional flood defence thrown in the mix. Traditionally, these are all hard engineering measures that have to meet their design requirements upon completion. The upcoming domain of Building with Nature in the flood safety sector is different in this sense. We expect that the bandwidth of uncertainty that is associated with the incorporation of natural processes in the design of civil infrastructures, and the changing behaviour of the structure itself in the maintenance phase, have implications for the governance of such infrastructures. 
Completion of the construction-phase is the default moment when hard infrastructure is assessed against predetermined and rather strict design requirements. After that, the structure is expected to demonstrate limited change, which can be compensated for by a detailed maintenance regime. Such a span of control seems unlikely for Building with Nature projects. In particular, Building with Nature projects require commissioners of civil infrastructures to acknowledge and perhaps embrace adaptivity in their policy (including legislation and financial agreements), another nudge in the paradigm shift in design management from a deterministic to a complexity perspective. To conclude, it should be noted that such modes of thinking may become more natural to certain academic disciplines.

This may be related to the object of study from which the particular discipline has originated. Landscape architecture, in particular, has traditionally worked with large spatial scales, natural processes and longer planning horizons - all attributes that belong to the landscape as the main object of study. A merging of landscape and infrastructure design efforts could therefore be a promising means to successfully organize Building with Nature projects. We can then again expect a redefinition for infrastructure and an expanded scope for its understanding - as Nijhuis and Jauslin already argued in 2015, less utilitarian, but as armatures for the facilitation of functional, social and ecological interaction. 
de Hoog, M., Sijmons, D., \& Verschuren, S. (1998). Herontwerp van het Laagland. In D.H. Frieling (Ed.), Het Metropolitane Debat. Thoth.

COST. (2014, November). Memorandum of Understanding for the implementation of a European Concerted Research Action designated as COST Action TD1408: Interdisciplinarity in research programming and funding cycles (INTREPID). https://www.cost.eu/actions/TD1408/\#tabs | Name:overview

COST. (2019). INTREPID Knowledge. Interdisciplinary and transdisciplinary research \& collaboration. https:// www.cost.eu/actions/TD1408/\#tabs|Name:overview

ESPON. (2020). Comparative Analysis of Territorial Governance and Spatial Planning Systems in Europe. https://www.espon.eu/planning-systems.

Gibbons, M., Limoges, C., Nowotny, H., Schwartzman, S., Scott, P., \& Trow, M. (2010). The new production of knowledge: The dynamics of science and research in contemporary societies. SAGE Publications Ltd, https://www.doi.org/10.4135/9781446221853

Hertogh, M.J.C.M., Brand, N., \& Visser, J. (2018). Integrated design. In H.L.M. Bakker \& J.P. de Klein (Eds.), Projects and People. Mastering Success (pp. 61-78). NAP-Process Industry network.

Hertogh, M.J.C.M., Baker, S.K., Staal, P.L., \& Westerveld, E. (2008). Managing Large Infrastructure Projects. Netlipse. http://netlipse.eu/media/18750/netlipse\%20book.pdf

Hertogh, M.J.C.M, \& Westerveld, E. (2010, January). Playing with Complexity. Management and organisation of large infrastructure projects. Erasmus University Rotterdam. http://hdl.handle.net/1765/18456

Hirsch Hadorn, G. H., Hoffmann-Riem, H., Biber-Klemm, S., Grossenbacher-Mansuy, W., Joye, D., Pohl, C., Wiesmann, U., Zemp, E., \& Jäger, J. (2008). Handbook of Transdisciplinary Research. Springer Publishing. http://doi.org/10.1007/978-1-4020-6699-3

Hoffman-Riem, H., Biber-Klemm, S., Grossenbacher-Mansuy, W., Hirsch Hadorn, G., Joye, D., Pohl, C., Wiesmann, U., \& Zemp, E. (2008). Idea of the handbook. In: Handbook of Transdiciplinary Research (pp. 3-17). Springer Publishing.

Hoonhout, B. (2019). Why more sand not always results in larger dunes. In A. Luijendijk \& A. van Oudenhoven (Eds.), The Sand Motor: A Nature-based Response to Climate Change (pp. 100-104). Delft University Publishers.

Krull, W. (2000). Beyond the Ivory Tower: Some Observations on External Funding of Interdisciplinary Research in Universities. In N. Stehr \& D. Weingart (Eds.), Practicing Interdisciplinarity (pp. 260-272). University of Toronto Press. https://doi.org/10.3138/9781442678729-015

Lyall, C. (2008 - June). A Short Guide to Designing Interdisciplinary Research for Policy and Practice. Edinburgh Research Explorer. https://www.research.ed.ac.uk/portal/en/publications/a-short-guide-to-designing-interdisciplinary-research-for-policy-and-practice(dfd150e8-1ef8-4f99-a78b-36bbb7d876d3).html

National Academy of Sciences, National Academy of Engineering, \& Institute of Medicine. (2005). Facilitating Interdisciplinary Research. The National Academies Press. 
Nijhuis, S., \& Jauslin, D. (2015). Urban landscape infrastructures: Designing operative landscape structures for the built environment. Research in Urbanism Series, 3, 13-34. https://doi.org/10.7480/rius.3.874

Pfirman, S., \& Martin, P. (2017). Facilitating interdisciplinary scholars. In R. Frodeman (Ed.), The Oxford Handbook of Interdisciplinarity (pp. 387-403). Oxford University Press. http://doi.org/10.1093/oxford$\mathrm{hb} / 9780198733522.013 .47$

ProClim. (1997, August). Visions of Swiss scientists: Research regarding sustainability and global change - science policy visions of Swiss scientists. SCNAT. http://proclim.ch/id/Yzz6d

Rhoten, D. \& Pfirman, S. (2007, October 22). Women, science and interdisciplinary ways of working. Inside Higher Education. https://www.insidehighered.com/views/2007/10/22/women-science-and-interdisciplinary-ways-working

Stive, R. J. H. (1999). Design features of the Sophia Rail Tunnel in the Betuweroute. Tunnelling and Underground Space Technology, 14(2), 141-149. https://doi.org/10.1016/s0886-7798(99)00028-0

van Oudenhoven, A., Aukes, E., \& Luijendijk, A. (2019). Towards multifunctional coastal management. In A. Luijendijk \& A. van Oudenhoven (Eds.), The Sand Motor: A Nature-based Response to Climate Change (pp. 14-17). Delft University Publishers.

van Zanten, S.C. (2016). Towards engineering the ecosystem services of a mega-nourishment. A forecast of the ecosystem service dynamics of the Sand Motor [MSc thesis]. Delft University of Technology.

Visser, J. L. (2020). Creating a New Perspective by Integrating Frames Through Design: An Exploratory Research into the What, Why, and How of Integrated Design (Doctoral dissertation). https://doi.org/10.4233/ uuid:11b45415-5342-4efa-aaf5-69592076cb3f

Voorendt, M. Z. (2017). A method for integrated and sustainable design: Five design stages. In B. Kothuis \& M. Kok (Eds.), Integral Design of Multifunctional Flood Defenses: Multidisciplinary Approaches and Examples (pp. 62-65). Delft University Publishers.

Wijnberg, K. (2019). Improving the above-water design of large sand nourishments: reflections. In A. Luijendijk, \& A. van Oudenhoven (Eds.), The Sand Motor: A Nature-based Response to Climate Change (pp. 104-105). Delft University Press. 




